\title{
ABT-737 promotes tBid mitochondrial accumulation to enhance TRAIL-induced apoptosis in glioblastoma cells
}

\author{
S Cristofanon ${ }^{1,2}$ and S Fulda ${ }^{\star, 1,2}$
}

To search for novel strategies to enhance the tumor necrosis factor-related apoptosis-inducing ligand (TRAIL)-induced apoptosis pathways in glioblastoma, we used the B-cell lymphoma 2/Bcl2-like 2-inhibitor ABT-737. Here we report that ABT-737 and TRAIL cooperate to induce apoptosis in several glioblastoma cell lines in a highly synergistic manner (combination index $<0.1$ ). Interestingly, the concerted action of ABT-737 and TRAIL to trigger the accumulation of truncated Bid (tBid) at mitochondrial membranes is identified as a key underlying mechanism. ABT-737 and TRAIL cooperate to cleave BH3-interacting domain death agonist (Bid) into its active fragment tBid, leading to increased accumulation of tBid at mitochondrial membranes. Coinciding with $\mathrm{tBid}$ accumulation, the activation of Bcl2-associated X protein (Bax), loss of mitochondrial membrane potential, release of cytochrome- $c$ and second mitochondria-derived activator of caspase (Smac) into the cytosol and caspase activation are strongly increased in cotreated cells. Of note, knockdown of Bid significantly decreases ABT-737- and TRAIL-mediated Bax activation and apoptosis. Also, caspase-3 silencing reduces ABT-737- and TRAIL-induced Bid cleavage and apoptosis, indicating that a caspase-3-driven, mitochondrial feedback loop contributes to Bid processing. Importantly, ABT-737 profoundly enhances TRAIL-triggered apoptosis in primary cultured glioblastoma cells derived from tumor material, underlining the clinical relevance. Also, ABT-737 acts in concert with TRAIL to suppress tumor growth in an in vivo glioblastoma model. In conclusion, the rational combination of ABT-737 and TRAIL cooperates to trigger tBid mitochondrial accumulation and apoptosis. This approach presents a promising strategy for targeting the apoptosis pathways in glioblastoma, which warrants further investigation.

Cell Death and Disease (2012) 3, e432; doi:10.1038/cddis.2012.163; published online 29 November 2012

Subject Category: Experimental Medicine

Glioblastoma is the most frequent primary malignant brain tumor with a very poor prognosis, thus calling for novel treatment strategies. ${ }^{1,2}$ Evasion of apoptosis (programmed cell death) is a hallmark of glioblastoma that promotes tumorigenesis and progression, as well as treatment resistance. ${ }^{3,4}$ The two key signaling pathways of apoptosis comprise the extrinsic (death receptor) pathway and the intrinsic (mitochondrial) pathway. ${ }^{3}$ In the death receptor pathway, the ligation of receptors of the tumor necrosis factor (TNF) superfamily, such as TNF-related apoptosis-inducing ligand (TRAIL) receptors, results in the formation of the deathinducing signaling complex (DISC) and activation of caspase-8, which subsequently leads to activation of effector caspases such as caspase-3..$^{5}$ In the mitochondrial pathway, the permeabilization of the outer mitochondrial membrane leads to the release of cytochrome- $c$ and second mitochondriaderived activator of caspase (Smac) from the mitochondrial intermembrane space into the cytosol, resulting in activation of caspase- 9 and $-3 .^{6}$ The release of mitochondrial proteins is tightly controlled by pro- and antiapoptotic proteins of the B-cell lymphoma 2 (Bcl-2) family. ${ }^{7}$ Both pathways are linked by the $\mathrm{Bcl}-2$ family protein $\mathrm{BH} 3$-interacting domain death agonist (Bid), which is cleaved by caspase- 8 into truncated Bid (tBid) that in turn translocates to mitochondrial membranes to initiate mitochondrial outer-membrane permeabilization. ${ }^{8}$ In addition, caspase-3 can process Bid into tBid, thereby promoting a feedback amplification loop to cause further mitochondrial perturbations. ${ }^{9}$

Proapoptotic TRAIL receptor agonists represent promising therapeutics in oncology, given their ability to trigger the cell's intrinsic death program, preferentially, in cancer versus normal cells, and are currently being evaluated in early clinical trials. ${ }^{10,11}$ However, primary or acquired resistance of glioblastoma toward TRAIL calls for alternative approaches to restore TRAIL sensitivity. Resistance to TRAIL may be caused by increased expression of antiapoptotic molecules

\footnotetext{
${ }^{1}$ Institute for Experimental Cancer Research in Pediatrics, Goethe-University, Frankfurt, Germany and ${ }^{2}$ University Children's Hospital, Ulm, Germany ${ }^{*}$ Corresponding author: S Fulda, Institute for Experimental Cancer Research in Pediatrics, Goethe-University, Komturstr. 3a, Frankfurt 60528, Germany. Tel: + 4969 67866557; Fax: + 4969 6786659157; E-mail: simone.fulda@kgu.de Keywords: apoptosis; TRAIL; ABT-737

Abbreviations: Bak, Bcl2-antagonist/killer; Bax, Bcl2-associated X protein; Bcl-2, B-cell lymphoma 2; Bcl- $\mathrm{X}$ L, Bcl2-like 2; BH3, Bcl-2 homology domain 3; Bid, BH3-interacting domain death agonist; Bim, Bcl2-like 11; CAM, chorioallantoic membrane; Cl, combination index; DISC, death-inducing signaling complex; DTT, ditiotreitolo; FACS, fluorescence-activated cell sorting; FADD, Fas-associated death domain; $\mathrm{I}_{\kappa} \mathrm{B} \alpha$, nuclear factor of kappa light polypeptide gene enhancer in B-cellinhibitor, alpha; Mtch2, mitochondrial carrier 2; MTT, 3-(4,5-dimethylthiazol-2-yl)-2,5-diphenyltetrazolium bromide; NF- $\kappa$ B, nuclear factor of kappa light polypeptide gene enhancer in B cell; PTEN, phosphatase and tensin homolog; RNAi, RNA interference; Smac, second mitochondria-derived activator of caspase; tBid, truncated Bid; TNF, tumor necrosis factor; TRAIL, tumor necrosis factor-related apoptosis-inducing ligand; TRAIL-R, TRAIL receptor

Received 26.4.12; revised 31.8.12; accepted 11.9.12; Edited by P Salomoni
} 
including antiapoptotic Bcl-2 family proteins. ${ }^{12}$ Upregulation of the prosurvival proteins $\mathrm{Bcl}-2$ and $\mathrm{Bcl} 2$-like 2 ( $\left.\mathrm{Bcl}-\mathrm{X}_{\mathrm{L}}\right)$ and downregulation of Bcl2-associated $X$ protein (Bax) have been described in recurrent glioblastoma before treatment. ${ }^{13,14}$ Because the ratio of pro- versus antiapoptotic $\mathrm{Bcl}-2$ proteins is considered to have an important role in regulating the susceptibility of cancer cells to undergo apoptosis, shifting this balance towards apoptosis provides a powerful means to initiate apoptosis. ${ }^{7}$ To antagonize prosurvival $\mathrm{Bcl}-2$ proteins, $\mathrm{Bcl}-2$ homology domain 3 (BH3)mimetics, that is, small molecules that have structural or functional similarities to $\mathrm{BH} 3-$ only proteins, were recently developed and are presently under preclinical and clinical evaluation. ${ }^{6}$ One of the most advanced and well-characterized $\mathrm{BH} 3$ mimetics is $\mathrm{ABT}-737$, which predominantly binds to $\mathrm{Bcl}-2, \mathrm{Bcl}-\mathrm{X}_{\mathrm{L}}$ and $\mathrm{Bcl}-\mathrm{w}$, while having low affinity to myeloid cell leukemia sequence $1 .{ }^{15}$ Recently, ABT-737 was reported to exert antitumor activity as single agent in glioblastoma cells in vitro. ${ }^{16}$ To search for novel strategies to target the apoptosis signaling pathways for the treatment of glioblastoma, we investigated the combination of ABT-737 and TRAIL to target the intrinsic and extrinsic pathways of apoptosis in the present study.

\section{Results}

ABT-737 enhances TRAIL-induced antitumor activity against glioblastoma in vitro and in vivo. To examine whether the neutralization of antiapoptotic Bcl-2 family proteins can enhance TRAIL-induced cell death, we selected five glioblastoma cell lines (i.e., U87MG, U118MG, T98G, U138MG and A172), which are heterogeneous for p53 and PTEN status (Supplementary Table 1), two key signaling components that are often altered in glioblastoma. ${ }^{17} \mathrm{~A}$ survey of pro- and antiapoptotic Bcl-2 proteins revealed that they are expressed in these cell lines at variable levels (Supplementary Figure 1a). Importantly, ABT-737 enhanced TRAIL-mediated reduction of cell viability in several glioblastoma cell lines in a highly synergistic manner as calculated by combination index (CI) (Figure 1a, Supplementary Table 2a). To validate these findings in clinical tumor material, we extended our studies to primary cultured glioblastoma samples obtained from surgical specimens. Of note, ABT-737 and TRAIL synergistically reduced cell viability of primary cultured glioblastoma cells (Figure $1 \mathrm{~b}$, Supplementary Table 2b). By comparison, ABT-737 and TRAIL did not significantly reduce cell viability of human fibroblasts at concentrations that synergized to reduce cell viability of glioblastoma cells (Supplementary Figure $1 \mathrm{~b}$ ).

To investigate whether ABT-737 enhances TRAIL-induced cell death not only in monolayer cultures in vitro but also in a three-dimensional tumor model in vivo, we used the chorioallantoic membrane (CAM) model, an established in vivo tumor model, for example, for anticancer drug testing. ${ }^{18-20}$ To this end, U87MG glioblastoma cells were seeded on the CAM of chicken embryos, allowed to form tumors, and were treated with ABT-737 and/or TRAIL for three consecutive days. Importantly, the combination treatment with ABT-737 and TRAIL cooperated to suppress tumor growth, whereas neither ABT-737 nor TRAIL as single agent inhibited tumor growth
(Figures 1c and d). Together, these findings demonstrate that ABT-737 enhances TRAIL-induced antitumor activity against glioblastoma in vitro and in vivo.

ABT-737 cooperates with TRAIL to trigger caspase activation and caspase-dependent apoptosis. To elucidate the molecular mechanism of the synergistic interaction of TRAIL and ABT-737, we focused our study on U87MG and U118MG cells, as the synergism was most pronounced in these cell lines (Supplementary Table 2a). Analysis of DNA fragmentation as a characteristic feature of apoptotic cell death showed that ABT-737 significantly enhanced TRAILinduced DNA fragmentation (Figure 2a). Moreover, ABT-737 promoted activation of caspase-8, -9 and -3 as indicated by increased processing of the proenzyme forms into active caspase fragments, that is, caspase- 8 into p43/41 and p18 fragments, caspase- 9 into p37/35 fragments and caspase- 3 into $\mathrm{p} 17 / 12$ fragments (Figure $2 \mathrm{~b}$ ). Addition of the broadrange caspase-inhibitor zVAD.fmk completely rescued loss of cell viability by TRAIL and ABT-737 (Figure 2c). To investigate whether caspase inhibition has an effect on long-term survival, we also assessed colony formation. Of note, zVAD.fmk significantly inhibited TRAIL/ABT-737mediated suppression of colony formation (Figure 2d, Supplementary Figure 2). Together, this set of experiments demonstrates that ABT-737 and TRAIL cooperate to trigger activation of caspases and caspase-dependent apoptosis.

No effect of ABT-737 on TRAIL receptor (TRAIL-R) 1/2 expression, TRAIL-induced DISC formation or complex II assembly. Next, we systematically investigated whether ABT-737 enhances signaling via the extrinsic pathway of apoptosis. To this end, we assessed surface expression of agonistic TRAIL receptors by flow cytometry, because the cooperative action of ABT-737 and TRAIL has previously been attributed to NF- $\kappa$ B (nuclear factor of kappa light polypeptide gene enhancer in B cell)-mediated upregulation of TRAIL-R2. ${ }^{21}$ U87MG and U118MG cells displayed low TRAIL-R1 levels in line with a recent study reporting frequent epigenetic silencing of TRAIL-R1 in glioblastoma. $^{22}$ Treatment with ABT-737 had no effect on TRAIL-R1 or -R2 expression, whereas exposure to TRAIL or TRAIL plus ABT-737 resulted in reduced TRAIL-R2 surface expression (Supplementary Figure 3a), consistent with its internalization upon ligand binding. ${ }^{23}$ Also, ectopic expression of $I_{\kappa} \mathrm{B} \alpha$ superrepressor did not alter the sensitivity of glioblastoma cells to ABT-737- and TRAIL-induced apoptosis (Supplementary Figure $3 \mathrm{~b}$ ), indicating that the synergistic induction of apoptosis by ABT-737 and TRAIL in glioblastoma cells is not due to NF- $\kappa \mathrm{B}$-mediated upregulation of TRAIL-R2 as reported in other cancer cell lines. ${ }^{21}$ Furthermore, analysis of the DISC in response to TRAIL receptor ligation revealed no alterations in the recruitment of Fasassociated death domain (FADD) or caspase-8 to activated TRAIL receptors in the presence or absence of ABT-737 (Supplementary Figure $3 \mathrm{c}$ ). In addition, the aggregation of FADD, caspase-8 and receptor-interacting serine-threonine kinase 1 into the cytosolic complex II upon TRAIL stimulation was not affected by the addition of ABT-737 (Supplementary Figure $3 d$ ). Together, this set of data indicates that 
a

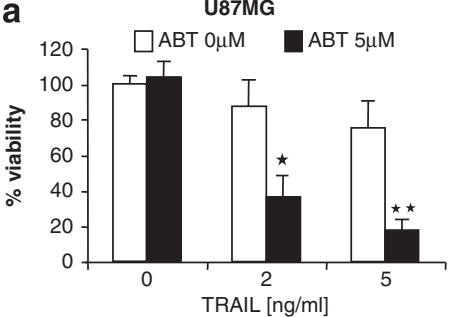

T98G

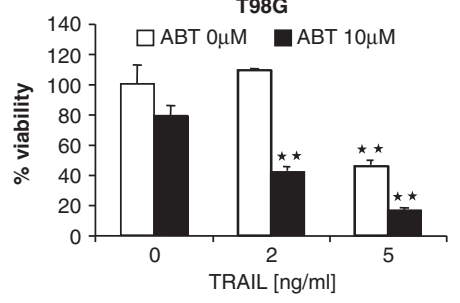

A172

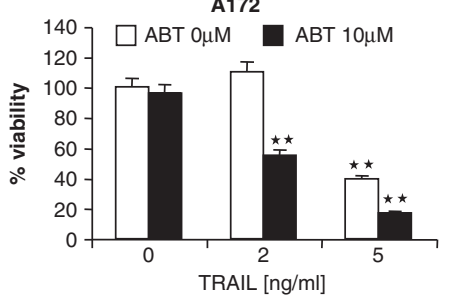

U118MG

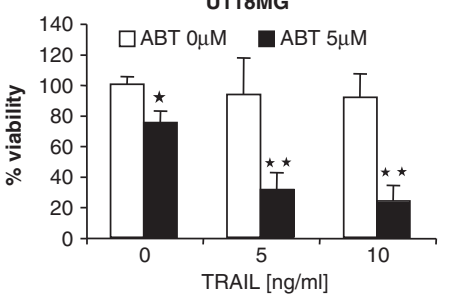

U138MG

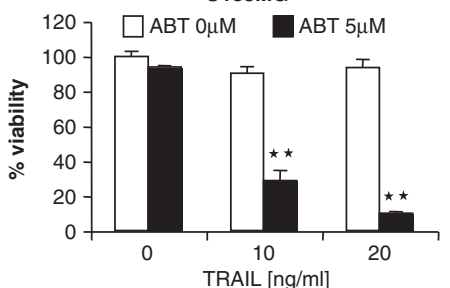

b
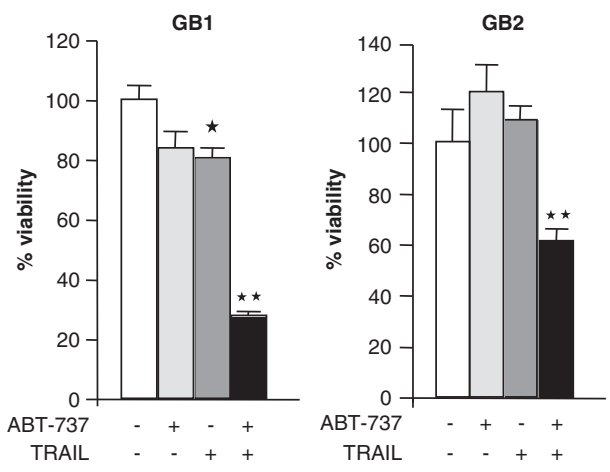

c
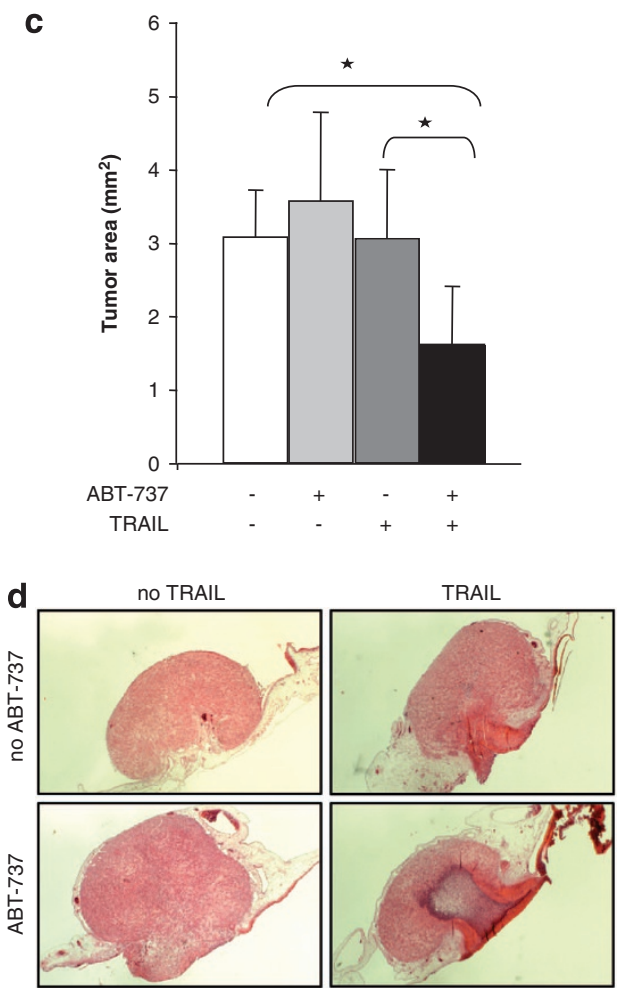

Figure 1 ABT-737 enhances TRAlL-induced antitumor activity against glioblastoma cells in vitro and in vivo. (a) Glioblastoma cells were treated with indicated concentrations of ABT-737 and/or TRAIL for $24 \mathrm{~h}$. Cell viability was determined by 3-(4,5-dimethylthiazol-2-yl)-2,5-diphenyltetrazolium bromide (MTT) assay and is expressed as percentage of untreated controls. Data represent mean + S.E.M. of three independent experiments performed in triplicate $\left({ }^{*} P<0.005\right.$ and ${ }^{* *} P<0.001$, comparing samples in the presence and absence of ABT-737). (b) Primary glioblastoma cells were treated with $5 \mu \mathrm{M}$ (GB1) or $10 \mu \mathrm{M}$ (GB2) ABT-737 and/or $2 \mathrm{ng} / \mathrm{ml}$ (GB1) or $10 \mathrm{ng} / \mathrm{ml}$ (GB2) TRAIL for $24 \mathrm{~h}$. Cell viability was determined by MTT assay and is expressed as percentage of untreated controls. Data represent mean + S.E.M. of three independent experiments performed in triplicate $\left({ }^{\star \star} P<0.001\right.$ ). (c and d) U87MG cells were seeded on the CAM of chicken embryos and treated with $2.5 \mu \mathrm{M} \mathrm{ABT-737} \mathrm{and/or} 10 \mathrm{ng} / \mathrm{ml}$ TRAIL for 3 days. Tumor growth was analyzed using hematoxylin and eosin-stained paraffin sections of the CAM as described in Materials and Methods. Tumor area as percentage of the untreated control group (c) and representative pictures of hematoxylin and eosin-stained sections of the CAM (d) are shown. Data represent mean + S.E.M. of 10 samples per group $(* P 0.005)$. Similar results were obtained in two independent experiments

ABT-737-mediated sensitization of glioblastoma cells toward TRAIL is not due to changes in TRAIL receptor expression, formation of the TRAIL DISC or complex II assembly.

ABT-737 and TRAIL cooperate to promote Bid cleavage, accumulation of $\mathrm{tBid}$ at mitochondria, Bax activation and mitochondrial outer membrane permeabilization. To explore whether the synergistic induction of apoptosis by
ABT-737 and TRAIL involves a cross-talk between the extrinsic and the intrinsic apoptosis pathways, we analyzed the effect of the caspase-8-selective inhibitor zIETD.fmk on mitochondrial outer membrane permeabilization. Interestingly, the addition of zIETD.fmk attenuated Bax activation (Figure $3 a$ ) and significantly reduced loss of mitochondrial membrane potential in cells treated with ABT-737 and TRAIL (Figure $3 b$ ). These findings indicate that caspase-8 activity 

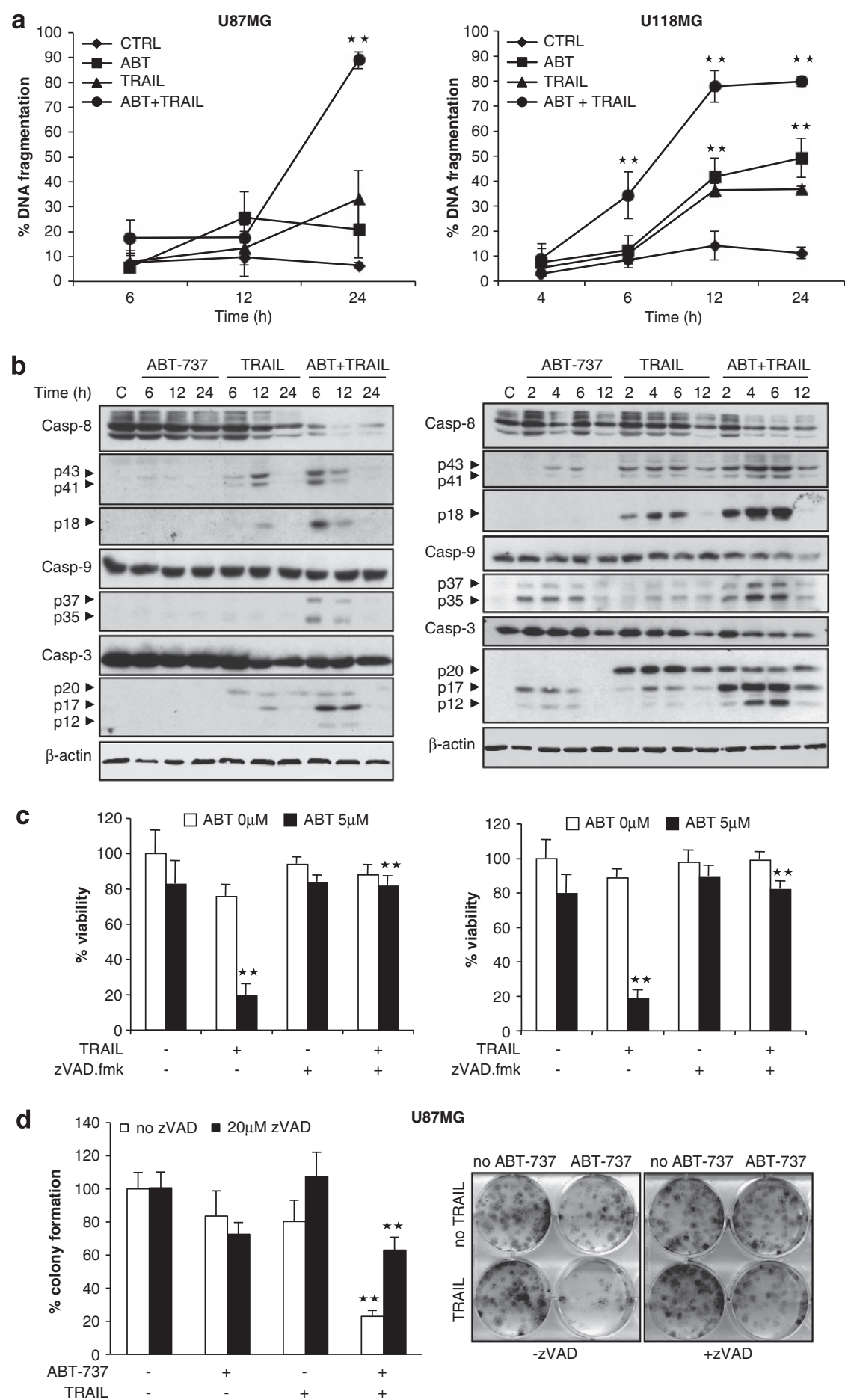

U87MG

Figure 2 ABT-737 synergizes with TRAIL to trigger caspase-dependent apoptosis. (a) U87MG (left panel) and U118MG (right panel) cells were treated for indicated times with $5 \mathrm{ng} / \mathrm{ml}$ (U87MG) or $10 \mathrm{ng} / \mathrm{ml}$ (U118MG) TRAIL and/or $5 \mu \mathrm{M} \mathrm{ABT-737.} \mathrm{Apoptosis} \mathrm{was} \mathrm{determined} \mathrm{by} \mathrm{FACS} \mathrm{analysis} \mathrm{of} \mathrm{DNA} \mathrm{fragmentation} \mathrm{of} \mathrm{propidium} \mathrm{iodide-stained}$ nuclei. Data represent mean \pm S.E.M. of three independent experiments performed in triplicate $\left.{ }^{* *} P<0.001\right)$. (b) U87MG (left panel) and U118MG (right panel) cells were treated for indicated times with $5 \mathrm{ng} / \mathrm{ml}$ (U87MG) or $10 \mathrm{ng} / \mathrm{ml}$ (U118MG) TRAIL and/or $5 \mu \mathrm{M}$ ABT-737. Caspase activation was analyzed by western blotting; arrowheads indicate caspase cleavage fragments. A representative experiment of three independent experiments is shown. (c) U87MG (left panel) and U118MG (right panel) cells treated for $24 \mathrm{~h}$ with $5 \mathrm{ng} / \mathrm{ml}$ (U87MG) or $10 \mathrm{ng} / \mathrm{ml}$ (U118MG) TRAIL, $5 \mu \mathrm{M}$ ABT-737 and/or $20 \mu \mathrm{M}$ zVAD.fmk. Cell viability was determined by MTT assay and is expressed as percentage of untreated controls. Data represent mean + S.E.M. of three independent experiments performed in triplicate. (d) U87MG cells were treated for $12 \mathrm{~h}$ with $5 \mathrm{ng} / \mathrm{ml}$ TRAIL and/or $5 \mu \mathrm{M}$ ABT-737 in the presence or absence of $20 \mu \mathrm{M}$ zVAD.fmk. Colonies were stained with crystal violet after 18 days and were counted under the microscope. One representative experiment (right panel) and the percentage of colony numbers compared with untreated control are shown (left panel). Data represent mean + S.E.M. of three independent experiments $\left({ }^{*} P<0.001\right)$ 
a

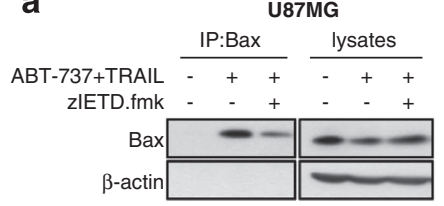

b

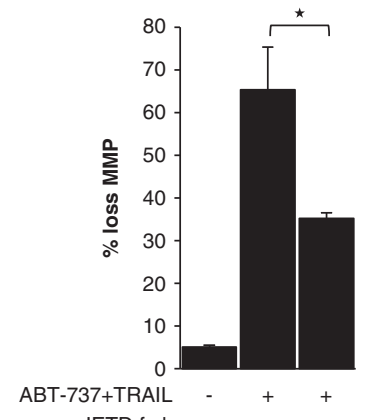

ZIETD.fmk
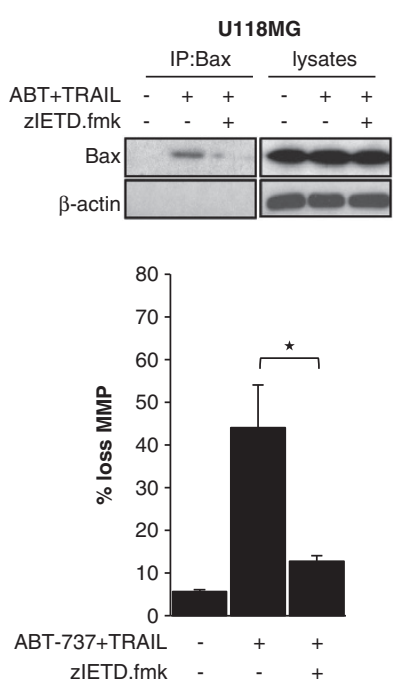

Figure 3 Caspase-8 contributes to activation of the intrinsic apoptosis pathway upon treatment with ABT-737 and TRAIL. (a) U87MG (left panel) and U118MG (right panel) cells were treated for $4 \mathrm{~h}$ with $5 \mathrm{ng} / \mathrm{ml}$ (U87MG) or $10 \mathrm{ng} / \mathrm{ml}$ (U118MG) TRAIL and $5 \mu \mathrm{M}$ ABT-737 in the presence or absence of $20 \mu \mathrm{M}$ caspase- 8 inhibitor (zIETD.fmk). Bax conformational change was determined by immunoprecipitation (IP); Bax expression in lysates served as control. (b) U87MG (left panel) and U118MG (right panel) cells were treated for $6 \mathrm{~h}$ with $5 \mathrm{ng} / \mathrm{ml}$ (U87MG) or $10 \mathrm{ng} / \mathrm{ml}$ (U118MG) TRAIL and $5 \mu \mathrm{M} \mathrm{ABT-737} \mathrm{in} \mathrm{the} \mathrm{presence} \mathrm{or} \mathrm{absence} \mathrm{of} 20 \mu \mathrm{M}$ caspase-8 inhibitor (zIETD.fmk). Mitochondrial transmembrane potential was assessed by FACS analysis. The percentage of cells with loss of mitochondrial potential with mean + S.E.M. of three independent experiments carried out in triplicate is shown $\left({ }^{*} P<0.005\right)$

contributes to mitochondrial outer membrane permeabilization upon the combined treatment with ABT-737 and TRAIL.

As activation of caspase-8 can cause cleavage of Bid into tBid, which in turn translocates to the mitochondria to initiate mitochondrial perturbations, ${ }^{8}$ we next examined whether Bid may link the extrinsic and intrinsic pathways in this model of apoptosis. Importantly, we detected tBid, the active cleavage product of Bid, predominately in cells that were cotreated with ABT-737 and TRAIL, whereas little Bid cleavage was observed upon treatment with either compound alone (Figure 4a). Because tBid inserts into mitochondrial membranes upon its cleavage, ${ }^{8}$ we then analyzed tBid levels in the mitochondrial fraction. Of note, ABT-737 and TRAIL acted in concert to trigger the accumulation of $\mathrm{tBid}$ at mitochondrial membranes (Figure 4b). As mitochondrial carrier 2 (Mtch2) has recently been reported to facilitate the recruitment of tBid to mitochondria, ${ }^{24}$ we examined whether the combination of TRAIL and ABT-737 causes an increase in Mtch2 expression. However, no upregulation of Mtch2 expression was found upon treatment with TRAIL, ABT-737 or the combination (Supplementary Figure 4).

As tBid triggers the conformational change of Bax that leads to Bax activation, ${ }^{8}$ we then assessed Bax activation by immunoprecipitating Bax via an active conformation-specific antibody. Importantly, ABT-737 profoundly enhanced TRAILinduced activation of Bax (Figure 4c). Furthermore, ABT-737 cooperated with TRAIL to induce loss of mitochondrial membrane potential and the release of cytochrome- $c$ and Smac from mitochondria into the cytosol (Figures $4 d$ and e).

These results show that ABT-737 and TRAIL cooperate to trigger mitochondrial translocation of $\mathrm{tBid}$, Bax activation and mitochondrial outer membrane permeabilization.

To explore whether tBid accumulation at the mitochondria and mitochondrial outer membrane permeabilization are general features of the synergism of ABT-737 and TRAIL, we extended our studies to additional glioblastoma cell lines. Similarly, increased translocation of tBid to mitochondrial membranes and enhanced loss of mitochondrial membrane potential upon cotreatment with ABT-737 and TRAIL were found in several glioblastoma cell lines (Supplementary Figure 5), in which ABT-737 and TRAIL synergistically induced apoptosis (Figure 1a, Supplementary Table 2a). This demonstrates that mitochondrial translocation of tBid and mitochondrial outer membrane permeabilization are common features of the synergistic induction of apoptosis by ABT-737 and TRAIL in glioblastoma cell lines.

Bid is a critical mediator of ABT-737- and TRAIL-induced apoptosis. To investigate the functional relevance of Bid for the synergistic induction of apoptosis by ABT-737 and TRAIL, we silenced Bid by RNA interference (RNAi) (Figure 5a). Importantly, knockdown of Bid reduced activation of Bax upon treatment with ABT-737 and TRAIL (Figure 5b). Also, silencing of Bid significantly decreased ABT-737- and TRAIL-induced apoptosis and loss of cell viability (Figures $5 c$ and d). To determine whether Bid knockdown simply delays cell death or affects long-term survival upon treatment with ABT-737 and TRAIL, we performed colony assays. Of note, Bid silencing significantly rescued the ABT-737/TRAIL-mediated suppression of colony formation (Figure 5e).

In addition to Bid, we also knocked down Bcl2-like 11 (Bim), another Bcl-2 family protein previously implicated in regulating sensitivity to $A B T-737 .{ }^{25}$ Notably, silencing of Bim in U118G cells did not affect ABT-737- and TRAIL-induced loss of cell viability (Supplementary Figure 6a). Moreover, because of the limited amount of Bim protein in U118G cells (Supplementary Figure 1a), we silenced Bid and Bim in T98G cells, a glioblastoma cell line that harbors high levels of both proteins (Supplementary Figure 1a). Similarly, knockdown of Bid, but not of Bim, significantly reduced ABT-737- and TRAIL-induced apoptosis in T98G cells (Supplementary Figure $6 \mathrm{~b})$. These findings demonstrate that Bid is an important mediator of the synergistic induction of apoptosis by ABT-737 and TRAIL.

Stabilization of tBid and caspase-3 amplification loop contribute to ABT-737- and TRAIL-induced apoptosis. As tBid has a short half-life due to proteasomal degradation, we hypothesized that ABT-737 might prevent the degradation of tBid and increase its half-life by promoting tBid insertion into mitochondrial membranes via inhibition of $\mathrm{Bcl}-2 / \mathrm{Bcl}-\mathrm{x}_{\mathrm{L}}$. To address this question, we treated T98G cells for $2 \mathrm{~h}$ with TRAIL in the absence or presence of ABT737 to induce the conversion of Bid to its tBid form. After this stimulation, cells were washed, the caspase-inhibitor zVAD.fmk was added to the culture medium to prevent further tBid cleavage and tBid levels were monitored over time. Interestingly, the addition of ABT-737 to TRAIL resulted 
a

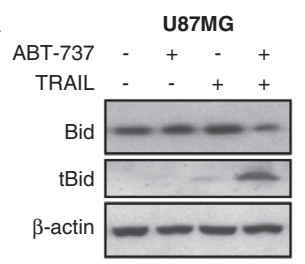

b

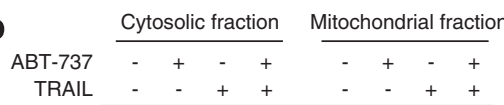
TRAIL $\quad-\quad-\quad+\quad+\quad-\quad-\quad+\quad+$

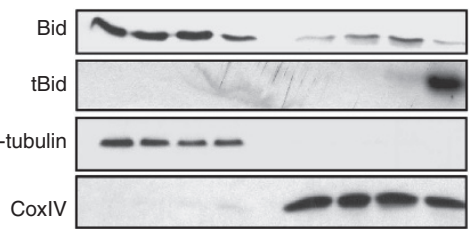

C

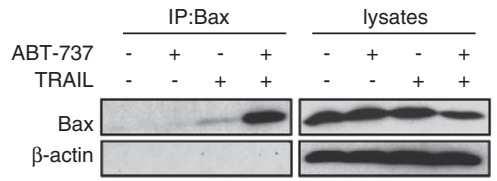

d

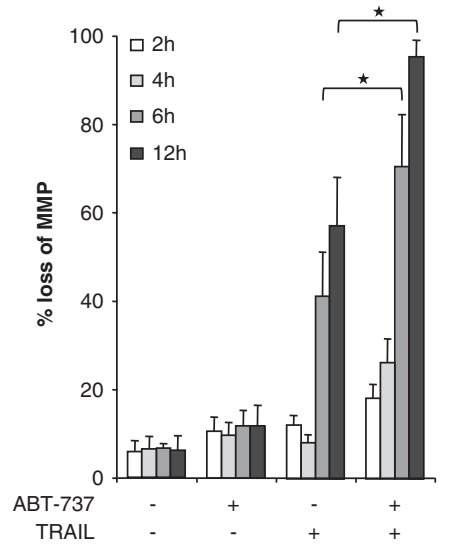

e

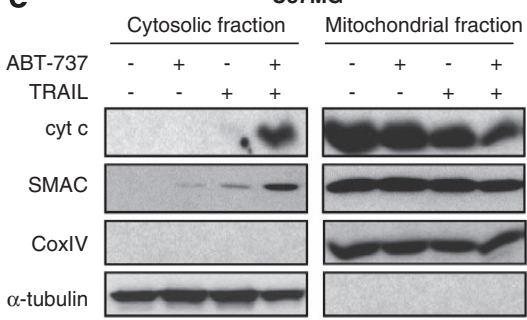

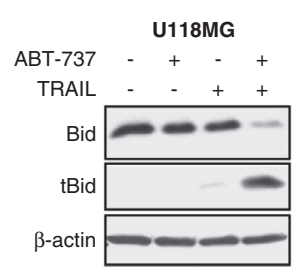
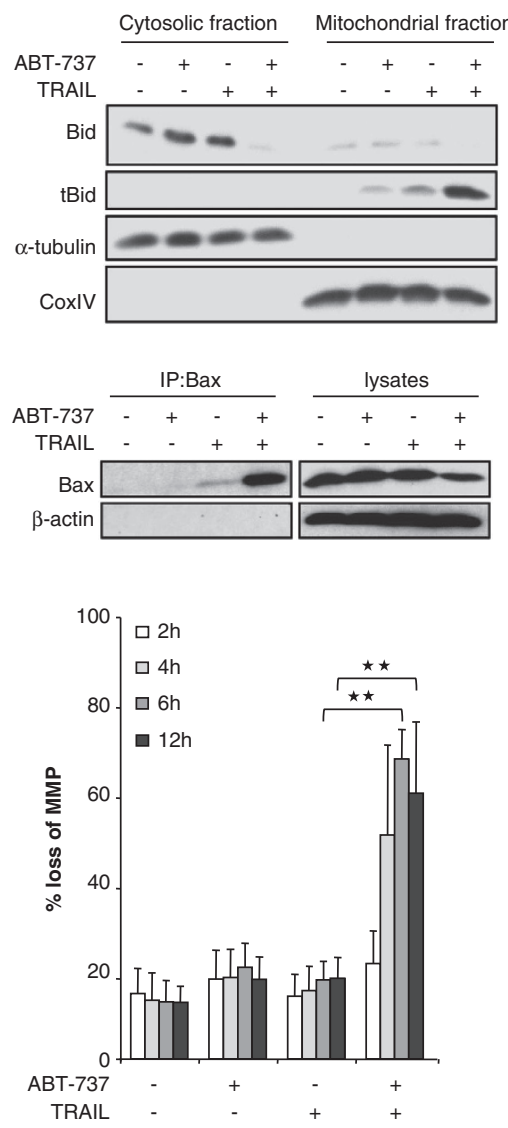

U118MG

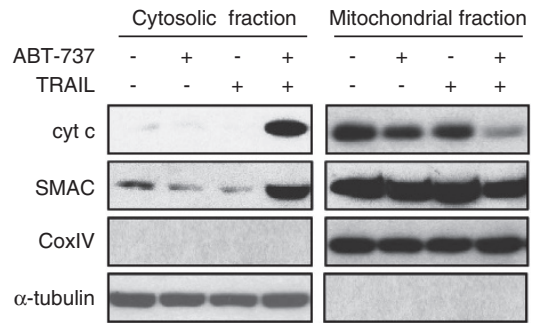

Figure 4 ABT-737 and TRAIL cooperate to promote mitochondrial accumulation of tBid and mitochondrial outer membrane permeabilization. (a-c) U87MG (left panel) and U118MG (right panel) cells were treated for $4 \mathrm{~h}$ with $5 \mathrm{ng} / \mathrm{ml}$ (U87MG) or $10 \mathrm{ng} / \mathrm{ml}$ (U118MG) TRAIL and/or $5 \mu \mathrm{M} \mathrm{ABT-737.} \mathrm{Bid} \mathrm{expression} \mathrm{was} \mathrm{analyzed} \mathrm{in} \mathrm{whole-cell} \mathrm{lysates} \mathrm{by}$ western blotting (a) or in cytosolic and mitochondrial fractions as described in Materials and Methods (b). In (c), Bax conformational change was determined by IP; Bax expression in lysates served as control. (d) U87MG (left panel) and U118MG (right panel) cells were treated for indicated times with $5 \mathrm{ng} / \mathrm{ml}$ (U87MG) or $10 \mathrm{ng} / \mathrm{ml}$ (U118MG) TRAlL and/or $5 \mu \mathrm{M}$ ABT-737. Mitochondrial transmembrane potential was assessed by FACS analysis. The percentage of cells with loss of mitochondria potential with mean + S.E.M. of three independent experiments in triplicate are shown $\left({ }^{*} P<0.005\right.$ and $\left.{ }^{* *} P<0.001\right)$. (e) U87MG (left panel) and U118MG (right panel) cells were treated for $6 \mathrm{~h}$ with $5 \mathrm{ng} / \mathrm{ml}$ (U87MG) or $10 \mathrm{ng} / \mathrm{ml}$ (U118MG) TRAIL and/or $5 \mu \mathrm{M}$ ABT-737. Expression of cytochrome-c and Smac in cytosolic and mitochondrial fractions was determined by western blot analysis. CoxIV and $\alpha$-tubulin served as purity and loading controls of the fractions. In (a-c and $\mathbf{e})$, representative experiments of three independent experiments are shown

in a longer half-life of tBid compared with treatment with TRAIL alone (Figure 6a).

In addition to caspase-8, caspase-3 has also been reported to cleave Bid into tBid. ${ }^{9}$ As we observed that ABT-737 substantially enhanced TRAIL-induced caspase-3 activation (Figure 2b), as well as proteolytic processing of Bid (Figure 4a), we asked whether caspase-3 contributes to Bid cleavage via a feedback amplification loop. To address this 
question, we silenced caspase-3 (Figure 6b) and then monitored Bid processing upon treatment with ABT-737 and TRAIL. Interestingly, caspase-3 knockdown attenuated cleavage of Bid into tBid (Figure 6b), decreased ABT-737- and TRAIL-induced apoptosis (Figure 6c), increased cell viability upon combination treatment (Supplementary Figure 7) and suppressed colony formation (Figure 6d). This indicates that caspase-3 contributes to proteolytic processing of Bid in a feedback amplification loop.

\section{Discussion}

In this study, we demonstrate that the simultaneous activation of the extrinsic and intrinsic apoptosis pathways by TRAIL and ABT-737, respectively, presents a promising approach to synergistically trigger apoptosis in glioblastoma cells in vitro and in vivo. This conclusion is supported by several individual pieces of evidence. First, ABT-737 enhances TRAIL-induced apoptosis in a highly synergistic manner as confirmed by calculation of $\mathrm{Cl}$. Second, synergistic cytotoxicity of ABT-737 and TRAIL occurs in several glioblastoma cell lines, underscoring the general relevance of this finding. Third, the combination treatment with ABT-737 and TRAIL proved to be effective to suppress tumor growth both in vitro and in an in vivo glioblastoma model. Fourth, this synergism not only occurs in established glioblastoma cell lines but also in primary glioblastoma cultures derived from tumor samples, underlining the clinical relevance of these results.

Furthermore, the novelty of the study resides in the identification of a new molecular mechanism, underlying the synergistic interaction of ABT-737 and TRAIL (Supplementary Figure 8). Accordingly, we demonstrate that ABT-737 and TRAIL act in concert to promote the cleavage of Bid into tBid. Although TRAIL triggers cleavage of Bid into tBid by activating caspase-8, ABT-737 facilitates the accumulation of tBid at mitochondrial membranes by neutralizing $\mathrm{Bcl}-2$ and $\mathrm{Bcl}-\mathrm{X}_{\mathrm{L}}$. This enhances the cross-talk between the extrinsic and the intrinsic apoptosis pathways and initiates a mitochondrial amplification loop, resulting in increased Bax activation, loss of mitochondrial membrane potential, the release of cytochrome- $c$ and Smac from mitochondria and caspasedependent apoptosis. Also, the combination treatment of ABT-737 and TRAIL contributes to Bid cleavage in a feedback loop via increased caspase-3 activity, as silencing of caspase3 attenuates processing of Bid into tBid. The critical role of Bid for the synergistic interaction of ABT-737 and TRAIL is underscored by knockdown experiments, showing that Bid silencing also attenuates ABT-737- and TRAIL-induced
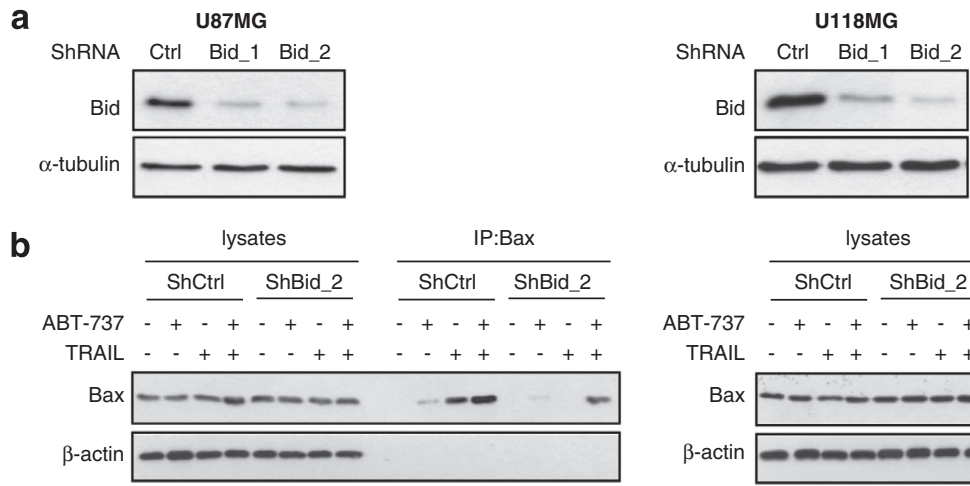

C
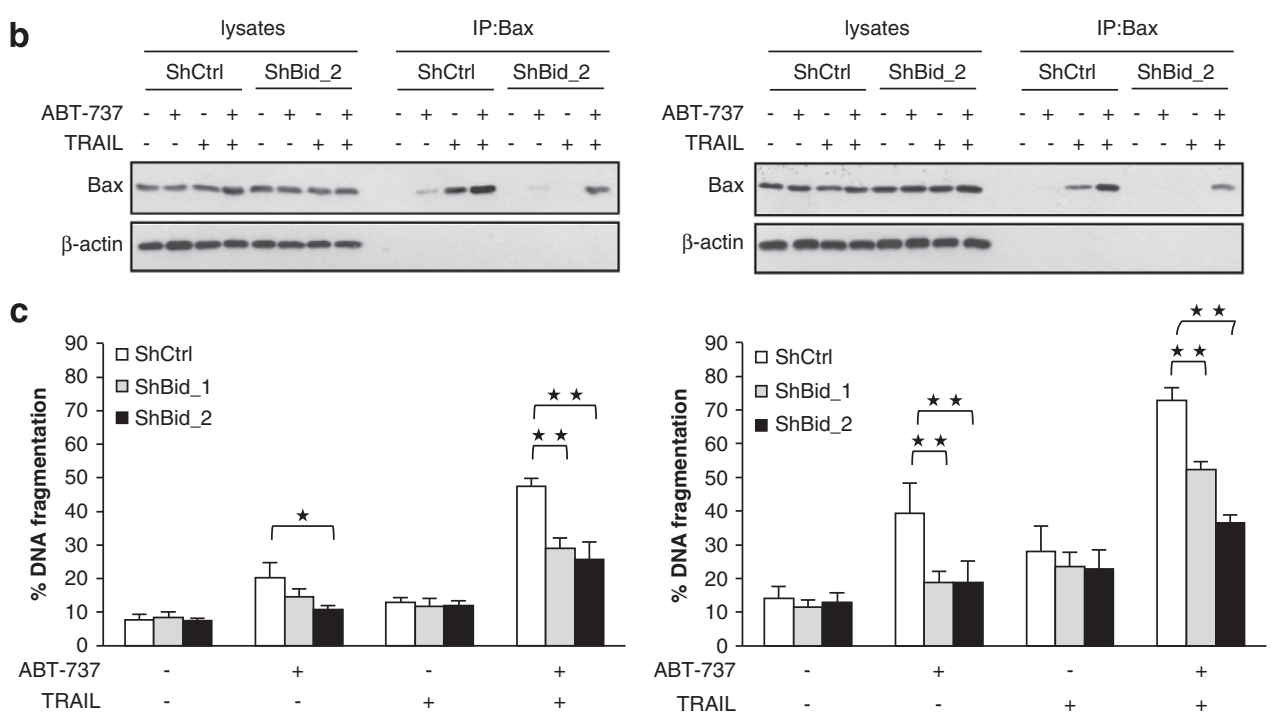

Figure 5 Bid is essential for ABT-737 and TRAIL-induced apoptosis. U87MG and U118MG cells were transduced with control vector (shCtrl) or a vector containing two different shRNA sequences against Bid (shBid_1 and shBid_2). (a) Expression of Bid was analyzed by western blotting. (b) U87MG (left panel) and U118MG (right panel) cells were treated for $4 \mathrm{~h}$ with $5 \mathrm{ng} / \mathrm{ml}$ (U87MG) or $10 \mathrm{ng} / \mathrm{ml}$ (U118MG) TRAIL and/or $5 \mu \mathrm{M}$ ABT-737. Bax conformational change was determined by IP, Bax expression in lysates served as control. A representative experiment of three independent experiments is shown. (c) U87MG (left panel) and U118MG (right panel) cells were treated for $24 \mathrm{~h}$ with $5 \mathrm{ng} / \mathrm{ml}$ (U87MG) or $10 \mathrm{ng} / \mathrm{ml}$ (U118MG) TRAIL and/or $5 \mu \mathrm{M}$ ABT-737. Apoptosis was determined by FACS analysis of DNA fragmentation of propidium iodide-stained nuclei. Data represent mean + S.E.M. of three independent experiments performed in triplicate $\left({ }^{*} P<0.005\right.$ and $\left.{ }^{* *} P<0.001\right)$. (d) U87MG (left panel) and U118MG (right panel) cells were treated for $24 \mathrm{~h}$ with $5 \mathrm{ng} / \mathrm{ml}$ (U87MG) or $10 \mathrm{ng} / \mathrm{ml}$ (U118MG) TRAIL and/or $5 \mu \mathrm{M}$ ABT-737. Cell viability was determined by MTT assay and is expressed as percentage of untreated controls. Data represent mean + S.E.M. of three independent experiments performed in triplicate. (e) U87MG (left panel) and U118MG (right panel) cells were treated for $12 \mathrm{~h}$ with $5 \mathrm{ng} / \mathrm{ml}$ (U87MG) or $10 \mathrm{ng} / \mathrm{ml}$ (U118MG) TRAIL and/or $5 \mu \mathrm{M} \mathrm{ABT-737.} \mathrm{Colonies} \mathrm{were} \mathrm{stained} \mathrm{with} \mathrm{crystal} \mathrm{violet} \mathrm{after} 18$ days and were counted under the microscope. One representative experiment (lower panel) and the percentage of colony numbers compared with untreated control are shown (upper panel). Data represent mean + S.E.M. of three independent experiments $\left({ }^{\star *} P<0.001\right)$ 

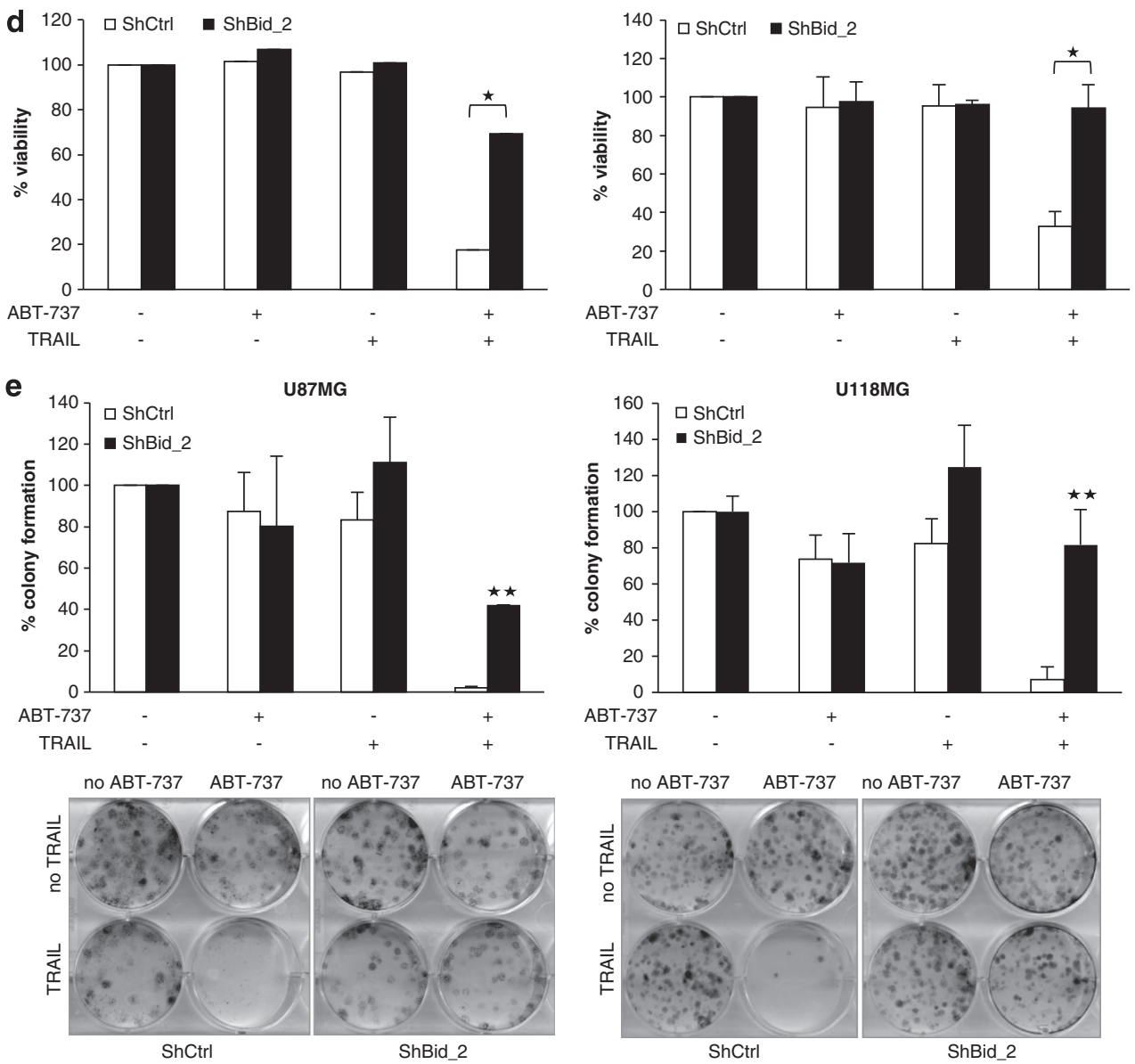

Figure 5 Continued

Bax activation and apoptosis. Thus, the combination treatment simultaneously activates the extrinsic and intrinsic apoptosis pathways and also enhances cross-talks between both pathways, resulting in synergistic induction of apoptosis.

A critical role of tBid in the regulation of mitochondrial outer membrane permeabilization has been shown in a recent study. ${ }^{26}$ Accordingly, tBid was reported to rapidly bind to mitochondrial membranes, where its $\mathrm{BH} 3$ domain facilitates the insertion of cytosolic Bax into the membrane, leading to activation and oligomerization of Bax and, subsequently, to membrane permeabilization. ${ }^{26}$ Antiapoptotic $\mathrm{Bcl}-2$ proteins, such as $\mathrm{Bcl}-\mathrm{X}_{\mathrm{L}}$, were shown to prevent Bax activation and mitochondrial outer membrane permeabilization via several mechanisms, that is, by directly binding to Bax and by sequestering tBid, thereby preventing Bax activation by tBid. ${ }^{26}$ In addition, $\mathrm{Bcl}-\mathrm{X}_{\mathrm{L}}$ and $\mathrm{Bcl}-2$ were recently found to stimulate retrotranslocation of Bax from the mitochondria into the cytoplasm, thereby sustaining Bax in its cytosolic inactive conformation. ${ }^{27}$ Interestingly, this retrotranslocation process was inhibited by ABT-737, resulting in accumulation of Bax on the mitochondrial outer membrane, where it acquired its active conformation. ${ }^{27}$ Thus, ABT-737 can increase the levels of both tBid and Bax at the outer mitochondrial membrane that are free to interact, thereby promoting the ability of tBid to trigger Bax oligomerization and activation.

Figure 6 Stabilization of tBid and caspase-3 amplification loop contributes to ABT-737 and TRAIL-induced apoptosis. (a) T98G cells were treated for $2 \mathrm{~h}$ with $2 \mathrm{ng} / \mathrm{ml}$ TRAIL and $5 \mu \mathrm{M}$ ABT-737 or with $5 \mathrm{ng} / \mathrm{ml}$ TRAIL. Then, cells were washed three times to remove all residual TRAIL and incubated with $20 \mu \mathrm{M}$ zVAD.fmk for indicated times. The tBid protein expression was determined by western blotting. One representative experiment is shown, and similar results were obtained in two independent experiments. (b) U87MG and U118MG cells were transduced with control vector (shCtrl) or a vector containing two different shRNA sequences against Caspase-3 (shC3_1 and shC3_2). Expression of caspase-3 was analyzed by western blotting. U87MG (left panel) and U118MG (right panel) cells were treated for $4 \mathrm{~h}$ with $5 \mathrm{ng} / \mathrm{ml}$ (U87MG) or $10 \mathrm{ng} / \mathrm{ml}$ (U118MG) TRAIL and/or $5 \mu \mathrm{M}$ ABT-737. Expression of Bid was analyzed by western blot. $\alpha$-tubulin served as loading control. A representative experiment of three independent experiments is shown. (c) U87MG (left panel) and U118MG (right panel) cells were treated for $24 \mathrm{~h}$ with $5 \mathrm{ng} / \mathrm{ml}$ (U87MG) or $10 \mathrm{ng} / \mathrm{ml}$ (U118MG) TRAIL and/or $5 \mu \mathrm{M}$ ABT-737. Apoptosis was determined by FACS analysis of DNA fragmentation of propidium iodide-stained nuclei. Data represent mean + S.E.M. of three independent experiments performed in triplicate $\left({ }^{*} P<0.005\right.$ and ${ }^{*} P<0.001$ ). (d) U87MG (left panel) and U118MG (right panel) cells were treated for $12 \mathrm{~h}$ with $5 \mathrm{ng} / \mathrm{ml}$ (U87MG) or $10 \mathrm{ng} /$ $\mathrm{ml}$ (U118MG) TRAIL and/or $5 \mu \mathrm{M}$ ABT-737. Colonies were stained with crystal violet after 18 days and were counted under the microscope. One representative experiment (lower panel) and the percentage of colony numbers compared with untreated control are shown (upper panel). Data represent mean + S.E.M. of three independent experiments $\left({ }^{*} P<0.001\right)$ 
Together, our findings provide novel insights into the synergistic action of ABT-737 and TRAIL compared with previous studies on other cancers. ${ }^{21,28}$ Although Song et al. ${ }^{21}$ suggested that NF- $\kappa$ B-mediated increase of TRAIL-R2 accounts for the sensitization to TRAIL by ABT-737, we observed no differences in TRAIL-R2 surface levels upon treatment with $\mathrm{ABT}-737$. Also, NF- $\kappa \mathrm{B}$ inhibition by overexpression of $\mathrm{I} \kappa \mathrm{B} \alpha-\mathrm{SR}$ had no effect on $\mathrm{ABT}-737-$ and

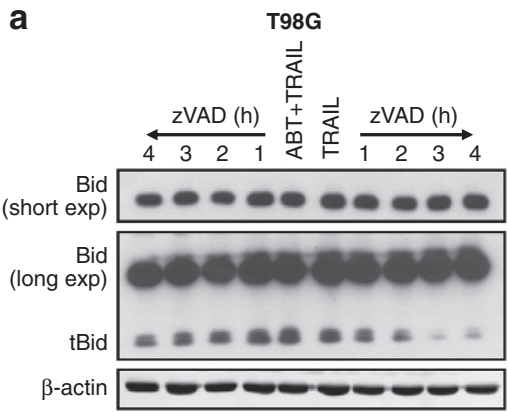

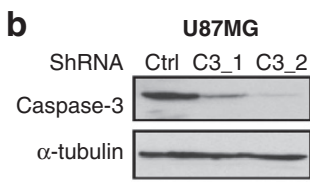

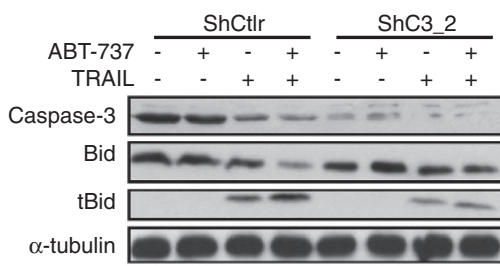

C

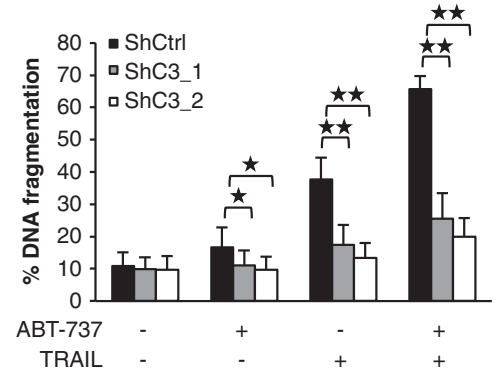

d
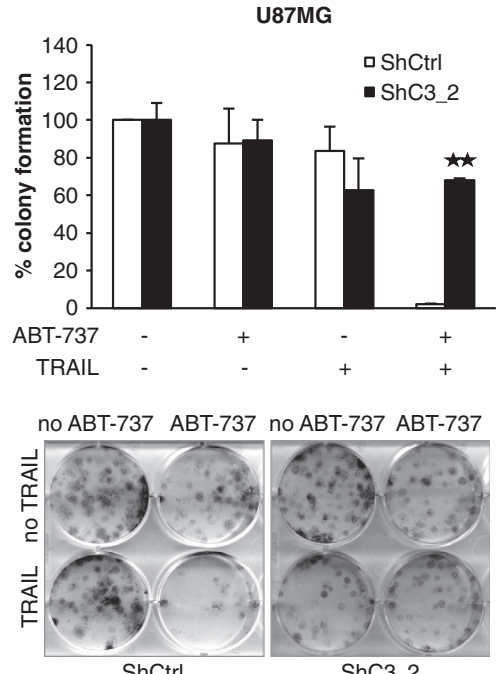

U118MG
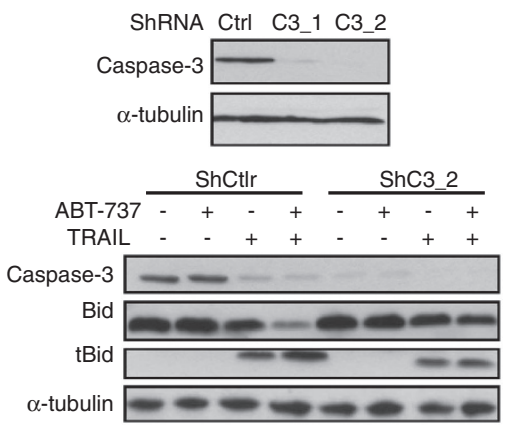

U118MG

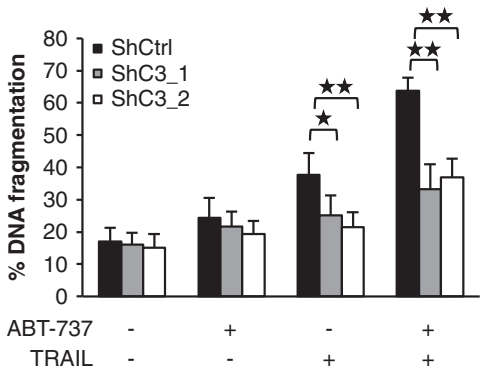

U118MG
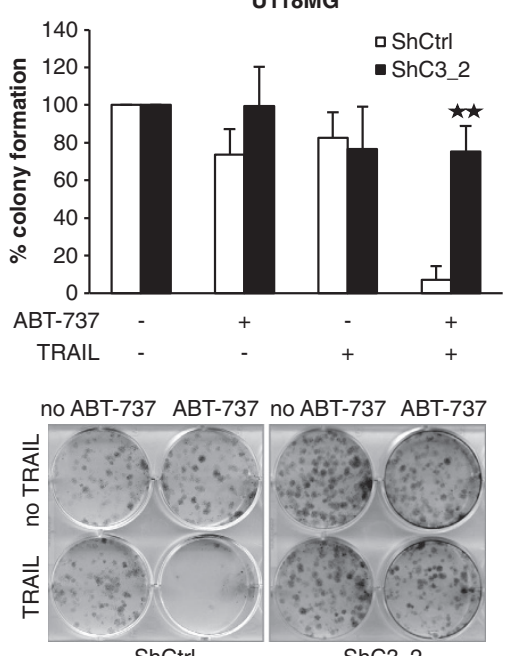

ShC3 2

ShCtrl 
TRAIL-induced apoptosis of glioblastoma cells in our study. In pancreatic carcinoma cells, Huang et al. ${ }^{28}$ reported that $\mathrm{ABT}-737$ releases the proapoptotic proteins Bim and Bcl2-antagonist/killer (Bak) from sequestration by $B c l-X_{L}$ or Bcl-2. However, Bim and Bak are unlikely the key mediators of ABT-737- and TRAIL-mediated apoptosis in glioblastoma cells, because we found that the combination treatment is also effective in glioblastoma cells with low expression levels of Bim and Bak, for example, in U87MG and U138MG cells. Together, these findings suggest that the molecular mechanisms underlying the synergism of ABT-737 and TRAIL likely depend on the tumor and/or cell type. This implies that it is necessary to evaluate the combination of ABT-737 and TRAIL in a given tumor in order to identify the signaling events that are responsible for the synergistic antitumor activity, thus underlining the importance of our work.

The translational relevance of our preclinical study is underscored as follows: This hypothesis-driven evaluation involves the rational combination of emerging treatment options for new targets, that is, the Bcl-2-inhibitor ABT-737 and the death receptor ligand TRAIL. Parallel experiments using primary tumor material highlight the clinical relevance of the findings. Importantly, the combination of ABT-737 plus TRAIL is also active in an in vivo model of glioblastoma. Thus, these data have important implications for the development of novel combination protocols for the treatment of glioblastoma. A derivative of ABT-737 as well as proapoptotic TRAIL receptor agonists are currently under evaluation in early clinical trials, ${ }^{10,11,29}$ suggesting that it is in principle feasible to translate this combination approach of ABT-737 and TRAIL into clinical testing. In conclusion, this study provides convincing evidence that ABT-737 in combination with TRAIL presents a promising novel strategy to trigger the apoptosis pathways in glioblastoma, which warrants further investigation.

\begin{abstract}
Materials and Methods
Cell culture and reagents. Glioblastoma cell lines were obtained from ATCC (Manassas, VA, USA). Glioblastoma cell lines and primary cultured glioblastoma cells were cultured as previously described. ${ }^{30}$ The p53 and PTEN status of glioblastoma cell lines is summarized in Supplementary Table $1{ }^{31}$ For combination treatment, cells were pretreated with ABT-737 for $1 \mathrm{~h}$ before TRAIL was added. ABT-737 was kindly provided by Abbott Laboratories (Abbott Park, IL, USA), TRAIL was purchased from R\&D Systems Inc. (Wiesbaden, Germany) and all chemicals from Sigma (Deisenhofen, Germany) unless indicated otherwise.
\end{abstract}

Determination of apoptosis and cell viability. Apoptosis was determined by fluorescence-activated cell sorting (FACS) analysis (FACScan; BD Biosciences, Heidelberg, Germany) of DNA fragmentation of propidium iodide-stained nuclei as previously described. ${ }^{32}$ Cell viability was assessed by 3-(4,5-dimethylthiazol-2-yl)-2,5-diphenyltetrazolium bromide assay according to the manufacturer's instructions (Roche Diagnostics, Grenzach, Germany).

Western blot analysis. Western blot analysis was carried out as previously described $^{33}$ using the following antibodies: caspase-8 (Alexis, Grünberg, Germany); caspase-3 (Cell Signaling, Beverly, MA, USA); caspase-9 and FADD (BD Biosciences); Bid (R\&D Systems Inc.); Bax NT (Upstate Biotechnology, Lake Placid, NY, USA); COXIV (Molecular Probes, Life Technologies, Darmstadt, Germany); Bax6A7and $\beta$-actin (Sigma); and goat-anti-mouse IgG, goat-anti-rabbit IgG and donkey-anti-goat IgG (Santa Cruz Biotechnology, Santa Cruz, CA, USA) conjugated to horseradish peroxidase. Enhanced chemiluminescence was used for detection (Amersham Bioscience, Freiburg, Germany).

Subcellular fractionation. Cytosolic and mitochondrial fractions were prepared as previously described. ${ }^{19}$ Briefly, $3 \times 10^{6}$ cells were harvested and washed twice in phosphate buffered salt. Pellets were resuspended in cytosolic lysis buffer $\left(2 \mathrm{mM} \mathrm{NaH}_{2} \mathrm{PO}_{4}, 16 \mathrm{mM} \mathrm{Na}_{2} \mathrm{HPO}_{4}, 150 \mathrm{mM} \mathrm{NaCl}, 500 \mathrm{mM}\right.$ sucrose, $1 \mathrm{mM}$ ditiotreitolo (DTT), $0.5 \mathrm{mg} / \mathrm{ml}$ digitonin and protease-inhibitor cocktail) for $5 \mathrm{~min}$ on ice. Cells were centrifuged for $1 \mathrm{~min}$ at 14000 r.p.m. at $4^{\circ} \mathrm{C}$. The resulting supernatant was collected as the cytosolic fraction and the pellet was resuspended in mitochondrial lysis buffer $(30 \mathrm{mM}$ Tris $\mathrm{HCl}, 150 \mathrm{mM} \mathrm{NaCl}, 1 \%$ TritonX, 10\% glycerol, $200 \mu \mathrm{M}$ phenylmethylsulfonyl fluoride, $2 \mathrm{mM}$ DTT and protease-inhibitor cocktail) for $2 \mathrm{~h}$ at $4^{\circ} \mathrm{C}$. The suspension was then centrifuged at 14000 r.p.m. for $20 \mathrm{~min}$ at $4{ }^{\circ} \mathrm{C}$. The resulting supernatant was kept as the mitochondrial fraction.

Determination of mitochondrial membrane potential. Tetramethylrhodamine ethyl ester $(1 \mu \mathrm{g} / \mathrm{ml}$; Sigma) was used to measure the mitochondrial transmembrane potential. Cells were incubated for $10 \mathrm{~min}$ at $37^{\circ} \mathrm{C}$ in the presence of the fluorochrome and immediately analyzed by flow cytometry. Loss of mitochondria potential is represented by the percentage of cells with decreased fluorescence.

RNAi-mediated silencing. HEK293T producer cells were transfected with $7.5 \mu \mathrm{g}$ pGIPZ-shRNAmir vector, $12.5 \mu \mathrm{g} \mathrm{pCMV-dR8.91} \mathrm{and} 1 \mu \mathrm{g} \mathrm{pMD2.G} \mathrm{using}$ calcium phosphate transfection. All pGIPZ-shRNAmir vectors were purchased from Thermo Fisher Scientific (Waltham, MA, USA): non-silencing control (ShCtrl): RHS4346, shC3_1: 5'-CATGTAATGGTATCTTAAA-3', shC3_2: 5'-CCGACAAGC TTGAATTTAT-3', shBid_1: $5^{\prime}$-GCCACTGTTTGGAAATAAA-3' and shBid_2: $5^{\prime}$-C CGTGATGTCTTTCACACA-3'. The virus containing supernatant was collected after $48 \mathrm{~h}$ and filtered using a $45-\mu \mathrm{m}$ filter. U87MG and U118MG cells were transduced by centrifugation at $1000 \times g$ for $1 \mathrm{~h}$ at room temperature in the presence of $8 \mu \mathrm{g} / \mathrm{ml}$ polybrene and selected for 2 weeks with $1 \mu \mathrm{g} / \mathrm{ml}$ puromycin.

Colony formation assay. For colony assay, cells were seeded after $12 \mathrm{~h}$ of treatment as single cells (200 cells per well) in six-well plates, and colony formation was assessed after additional 18 days by crystal violet staining with $0.75 \%$ crystal violet, $50 \%$ ethanol, $0.25 \% \mathrm{NaCl}$ and $1.57 \%$ formaldehyde.

Immunoprecipitation. Bax activation was determined by immunoprecipitation as previously described. ${ }^{34}$ Briefly, cells were lysed in CHAPS lysis buffer (10 mM HEPES, pH 7.4, $150 \mathrm{mM} \mathrm{NaCl}$ and 1\% CHAPS). An amount of $2 \mathrm{mg}$ protein was incubated with $16 \mu \mathrm{g}$ mouse anti-Bax antibody (clone 6A7; Sigma) overnight at $4^{\circ} \mathrm{C}$ followed by addition of $10 \mu \mathrm{l}$ pan-mouse IgG Dynabeads (Dako, Hamburg, Germany), incubated for $2 \mathrm{~h}$ at $4^{\circ} \mathrm{C}$, washed with CHAPS lysis buffer and analyzed by western blotting using rabbit anti-BaxNT antibody.

CAM assay. CAM assay was done as described previously. ${ }^{18}$ Briefly, $1 \times 10^{6}$ cells were implanted on fertilized chicken eggs on day 8 of incubation and were treated with $5 \mu \mathrm{M} \mathrm{ABT}-737$ and/or $10 \mathrm{ng} / \mathrm{ml}$ TRAIL for 3 days, sampled with the surrounding CAM, fixed in $4 \%$ paraformaldehyde, paraffin embedded, cut in $5-\mu \mathrm{m}$ sections and were analyzed by immunohistochemistry using $1: 1$ hematoxyline and $0.5 \%$ eosin. Images were digitally recorded at a magnification of $\times 2$ with an AX70 microscope (Olympus, Center Valley, PA, USA), and tumor areas were analyzed with ImageJ digital imaging software (NIH, Bethesda, MD, USA).

Statistical analysis. Statistical significance was assessed by Student's $t$-test (two-tailed distribution, two-sample, unequal variance). $\mathrm{Cl}$ was calculated as described by $\mathrm{Chou}^{35}$ using CalcuSyn software (Biosoft, Cambridge, UK).

\section{Conflict of Interest}

The authors declare no conflict of interest.

Acknowledgements. We thank $C$ Hugenberg for expert secretarial assistance and A Dittrich, S Baumgart and R Sauter for expert technical assistance. ABT737 was kindly provided by Abbott Laboratories. This work has been partially supported by grants from the Deutsche Forschungsgemeinschaft, European Community (ApopTrain, APO-SYS) and IAP6/18 (to SF).

1. Louis DN, Ohgaki H, Wiestler OD, Cavenee WK, Burger PC, Jouvet A et al. The 2007 WHO classification of tumours of the central nervous system. Acta Neuropathol 2007; 114: 97-109. 
2. Furnari FB, Fenton $T$, Bachoo RM, Mukasa $A$, Stommel JM, Stegh $A$ et al. Malignant astrocytic glioma: genetics, biology, and paths to treatment. Genes Dev 2007; 21 2683-2710.

3. Fulda S, Debatin KM. Extrinsic versus intrinsic apoptosis pathways in anticancer chemotherapy. Oncogene 2006; 25: 4798-4811.

4. Hanahan D, Weinberg RA. Hallmarks of cancer: the next generation. Cell 2011; 144 646-674.

5. Ashkenazi A. Targeting the extrinsic apoptosis pathway in cancer. Cytokine Growth Factor Rev 2008; 19: 325-331.

6. Fulda S, Galluzzi L, Kroemer G. Targeting mitochondria for cancer therapy. Nat Rev Drug Discov 2010; 9: 447-464.

7. Tait SW, Green DR. Mitochondria and cell death: outer membrane permeabilization and beyond. Nat Rev Mol Cell Biol 2010; 11: 621-632.

8. Billen LP, Shamas-Din A, Andrews DW. Bid: a Bax-like BH3 protein. Oncogene 2008 27(Suppl 1): S93-S104.

9. Slee EA, Keogh SA, Martin SJ. Cleavage of BID during cytotoxic drug and UV radiationinduced apoptosis occurs downstream of the point of $\mathrm{Bcl}-2$ action and is catalysed by caspase-3: a potential feedback loop for amplification of apoptosis-associated mitochondrial cytochrome c release. Cell Death Differ 2000; 7: 556-565.

10. Moretto P, Hotte SJ. Targeting apoptosis: preclinical and early clinical experience with mapatumumab, an agonist monoclonal antibody targeting TRAIL-R1. Expert Opin Investig Drugs 2009; 18: 311-325.

11. Yang A, Wilson NS, Ashkenazi A. Proapoptotic DR4 and DR5 signaling in cancer cells: toward clinical translation. Curr Opin Cell Biol 2010; 22: 837-844.

12. Fulda S. Tumor resistance to apoptosis. Int J Cancer 2009; 124: 511-515.

13. Strik H, Deininger M, Streffer J, Grote E, Wickboldt J, Dichgans J et al. BCL-2 family protein expression in initial and recurrent glioblastomas: modulation by radiochemotherapy. J Neurol Neurosurg Psychiatry 1999; 67: 763-768.

14. Krakstad $C$, Chekenya M. Survival signalling and apoptosis resistance in glioblastomas: opportunities for targeted therapeutics. Mol Cancer 2010; 9: 135

15. Oltersdorf T, Elmore SW, Shoemaker AR, Armstrong RC, Augeri DJ, Belli BA et al. An inhibitor of Bcl-2 family proteins induces regression of solid tumours. Nature 2005; 435 $677-681$.

16. Tagscherer KE, Fassl A, Campos B, Farhadi M, Kraemer A, Bock BC et al. Apoptosisbased treatment of glioblastomas with ABT-737, a novel small molecule inhibitor of Bcl-2 family proteins. Oncogene 2008; 27: 6646-6656.

17. McLendon R, Friedman A, Bigner D, VanMei E, Brat D, Mastrogianakis $G$ et al. Comprehensive genomic characterization defines human glioblastoma genes and core pathways. Nature 2008; 455: 1061-1068.

18. Vogler M, Walczak H, Stadel D, Haas TL, Genze F, Jovanovic M et al. Targeting XIAP bypasses Bcl-2-mediated resistance to TRAIL and cooperates with TRAIL to suppress pancreatic cancer growth in vitro and in vivo. Cancer Res 2008; 68: 7956-7965.

19. Naumann I, Kappler R, von Schweinitz D, Debatin KM, Fulda S. Bortezomib primes neuroblastoma cells for TRAIL-induced apoptosis by linking the death receptor to the mitochondrial pathway. Clin Cancer Res 2011; 17: 3204-3218.

20. Unterkircher T, Cristofanon S, Vellanki SH, Nonnenmacher L, Karpel-Massler G, Wirtz CR et al. Bortezomib primes glioblastoma, including glioblastoma stem cells, for TRAlL by increasing tBid stability and mitochondrial apoptosis. Clin Cancer Res 2011; 17: 4019-4030.

21. Song $\mathrm{JH}$, Kandasamy $\mathrm{K}$, Kraft AS. ABT-737 induces expression of the death receptor 5 and sensitizes human cancer cells to TRAIL-induced apoptosis. J Biol Chem 2008; 283 : 25003-25013.
22. Elias A, Siegelin MD, Steinmuller A, von Deimling A, Lass U, Korn B et al. Epigenetic silencing of death receptor 4 mediates tumor necrosis factor-related apoptosis-inducing ligand resistance in gliomas. Clin Cancer Res 2009; 15: 5457-5465.

23. Kohlhaas SL, Craxton A, Sun XM, Pinkoski MJ, Cohen GM. Receptor-mediated endocytosis is not required for tumor necrosis factor-related apoptosis-inducing ligand (TRAIL)-induced apoptosis. J Biol Chem 2007; 282: 12831-12841.

24. Zaltsman Y, Shachnai L, Yivgi-Ohana N, Schwarz M, Maryanovich M, Houtkooper RH et al. MTCH2/MIMP is a major facilitator of tBID recruitment to mitochondria. Nat Cell Biol 2010; 12: $553-562$

25. Deng J, Carlson N, Takeyama K, Dal Cin P, Shipp M, Letai A. BH3 profiling identifies three distinct classes of apoptotic blocks to predict response to ABT-737 and conventional chemotherapeutic agents. Cancer Cell 2007; 12: 171-185.

26. Lovell JF, Billen LP, Bindner S, Shamas-Din A, Fradin C, Leber B et al. Membrane binding by tBid initiates an ordered series of events culminating in membrane permeabilization by Bax. Cell 2008; 135: 1074-1084.

27. Edlich F, Banerjee S, Suzuki M, Cleland MM, Arnoult D, Wang C et al. $\mathrm{Bcl}-\mathrm{x}(\mathrm{L})$ retrotranslocates Bax from the mitochondria into the cytosol. Cell 2011; 145 : 104-116.

28. Huang S, Sinicrope FA. BH3 mimetic ABT-737 potentiates TRAIL-mediated apoptotic signaling by unsequestering Bim and Bak in human pancreatic cancer cells. Cancer Res 2008; 68: 2944-2951.

29. Wilson WH, O'Connor OA, Czuczman MS, LaCasce AS, Gerecitano JF, Leonard JP et al. Navitoclax, a targeted high-affinity inhibitor of BCL-2, in lymphoid malignancies: a phase 1 dose-escalation study of safety, pharmacokinetics, pharmacodynamics, and antitumour activity. Lancet Oncol 2010; 11: 1149-1159.

30. Opel D, Westhoff MA, Bender A, Braun V, Debatin KM, Fulda S. Phosphatidylinositol 3-kinase inhibition broadly sensitizes glioblastoma cells to death receptor- and drug-induced apoptosis. Cancer Res 2008; 68: 6271-6280.

31. Ishii N, Maier D, Merlo A, Tada M, Sawamura Y, Diserens AC et al. Frequent co-alterations of TP53, p16/CDKN2A, p14ARF, PTEN tumor suppressor genes in human glioma cell lines. Brain Pathol 1999; 9: 469-479.

32. Vogler M, Walczak H, Stadel D, Haas TL, Genze F, Jovanovic M et al. Small molecule XIAP inhibitors enhance TRAIL-induced apoptosis and antitumor activity in preclinical models of pancreatic carcinoma. Cancer Res 2009; 69: 2425-2434.

33. Fulda S, Sieverts H, Friesen C, Herr I, Debatin KM. The CD95 (APO-1/Fas) system mediates drug-induced apoptosis in neuroblastoma cells. Cancer Res 1997; 57: 3823-3829.

34. Hacker S, Dittrich A, Mohr A, Schweitzer T, Rutkowski S, Krauss J et al. Histone deacetylase inhibitors cooperate with IFN-gamma to restore caspase-8 expression and overcome TRAIL resistance in cancers with silencing of caspase-8. Oncogene 2009; 28 : 3097-3110.

35. Chou TC. The median-effect principle and the combination index for quantitation of synergism and antagonism. In: Chou TC (ed). Synergism and Antagonism in Chemotherapy. Academic Press: San Diego, USA, 1991. pp 61-102.

Cell Death and Disease is an open-access journal published by Nature Publishing Group. This work is licensed under the Creative Commons Attribution-NonCommercial-No Derivative Works 3.0 Unported License. To view a copy of this license, visit http://creativecommons.org/licenses/by-nc-nd/3.0/

Supplementary Information accompanies the paper on Cell Death and Disease website (http://www.nature.com/cddis) 